\title{
Effect of dietary intake on serum calcium levels and bone mineral density of menopausal women of Ludhiana city, India
}

\author{
Shruti Jain* \\ Department of Food and Nutrition, Punjab Agricultural University, Ludhiana (Punjab) \\ India

\section{Subhashini Verma} \\ Department of Food and Nutrition, Punjab Agricultural University, Ludhiana (Punjab) \\ India \\ *Corresponding author. E-mail: shruti_sahaji@yahoo.com
}

\begin{abstract}
Sixty women of 45-55 years, belonging to middle income group were selected on basis of their Bone Mineral Density (BMD) from a - "Clinic After Forty" of Ludhiana city, Punjab. Serum calcium and BMD were tested using techniques called o-Cresolphthalein complexone (OCPC) method and Dual energy X-ray Absorptiometry (DEXA) respectively. Subjects were given nutrition counseling (NC) twice a month for a period of 4 months. Assessment of nutritional status was done by dietary survey and anthropometric parameters before and after study. Dietary survey revealed that daily intake of milk and milk products $(p<0.05)$, roots and tubers $(p<0.01)$, green leafy vegetables $(G L V s)(p<0.01)$, other vegetables and fruits $(p<0.01)$ increased significantly whereas intake of sugar and jaggery and fats and oils $(p<0.01)$ decreased significantly after NC. Intake of beta carotene, vitamin $C$, iron, calcium and phosphorus also increased significantly. Mean weight, Body Mass Index (BMI) waist-circumference, hip circumference and WHR decreased significantly after NC. Biochemical assessment revealed significant improvement in serum calcium levels and BMD from $7.82 \mathrm{mg} / \mathrm{dl}$ to $8.99 \mathrm{mg} / \mathrm{dl}(\mathrm{p}<0.01)$ and -2.2 to -2.01 $(p<0.01)$ respectively. Subjects were classified as osteopenic and osteoporotic on basis of their t-scores. Majority of the subjects were osteopenic and the rest were osteoporotic. But after NC \%age of osteopenic subjects increased while \%age of osteoporotic subjects decreased. Study emphasized the importance of NC to bring about positive changes in dietary intake of menopausal women which in turn improved their serum calcium levels and BMD. Hence NC can be taken as an effective and sustainable tool to tackle osteoporosis as it is a serious public health issue among Indian menopausal women.
\end{abstract}

Keywords: Bone Mineral Density, Menopausal women, Osteoporosis, Serum Calcium

\section{INTRODUCTION}

Osteoporosis or porous bone disease is a disease characterized by a low bone mass and structural deterioration of bone tissues leading to bone fragility and an increased susceptibility to fractures of hip, spine and wrist. It is a disease in which both the quantity and quality of bones are reduced. Quantity is measured from Bone Mineral Density BMD. Quality is affected by many factors including the degree of mineralization, connectivity of the bony trabeculae, the quality of the collagen fibres, and the health of the bone cells. During childhood, the bone formation occurs at fastest rate and the bone resorption is very slow. After attaining maximum height, still bone formation continues at faster pace than resorption until around early twenties (peak bone mass attainment). In the later twenties, bone mass remains

\section{Article Info}

DOI:10.31018/jans.v10i4.1921

Received: October 19, 2018

Revised: November 18, 2018

Accepted: November 28, 2018

\section{How to Cite}

Jain, S. and Verma, S. (2018). Effect of dietary intake on serum calcium levels and bone mineral density of menopausal women of Ludhiana city, India. Journal of Applied and Natural Science, 10 (4): $1281-1285$ 
architectural deterioration of bone tissue leading to enhanced bone fragility and consequently increasing the fracture risk among elderly people (Dempster and Lindsay 1993). However, osteoporosis is the sub-clinical or symptomless condition and becomes clinically evident only when a person suffers a fracture. Besides the uncontrollable factors such as age, sex and menopause, several controllable factors such as multiparity, physical activity, nutritional status and drugs affect osteoporosis. (Deepti et al 2006). It is basically classified into two major categories, osteoporosis I and Osteoporosis II. The type I occur in women within few years of menopause because of cessation of ovarian production of estrogen. It is also known as post menopausal osteoporosis. Type II is also called the age associated osteoporosis and it is not linked to the female gender (Chowdhary 2012).

The intake of calcium and protein rich foods during childhood and adolescence is an important contributor to peak bone mass. They are also crucial for maintenance of bone mass and prevention of bone loss in adults. As women go through menopause their metabolism slows down, their vitamin requirements increase but calorie requirements decrease. So the modification in the diet intake becomes imperative keeping in mind the physiological state in which these women are with decline in production of estrogen in body. Complex carbohydrates should be preferred to simple carbohydrates as they are digested more slowly than simple carbohydrates, which enter blood stream directly from digestive tract. Intake of coffee, caffeine products and carbonated drinks should also be restricted as they increase urinary loss of calcium and decrease bone mass. The importance of nutrition intervention is paramount. Nutrition education aims at importance of balanced diet and healthy eating habits for improvement and management of health and nutritional status thus reducing potential complications, promoting physiological and psychological well being and encouraging healthy eating habits in menopausal women. Hence a well balanced diet along with stress management and routine exercise help women in better management of menopausal problems and associated complications. (Prasad 2010). So, the objective of the investigation was to find out impact of dietary intake on serum calcium lever bone mineral density of menopausal women.

\section{MATERIALS AND METHODS}

The study was conducted in lqbal Nursing Home of Ludhiana city, India as a "Clinic After Forty" is being run for the women there. A sample of 60 post-menopasual women between the age-group of $45-55$ years belonging to middle income group were selected on the basis of their BMD which was tested using a technique known as Dual En- ergy X-ray Absorptiometry (DEXA). Those having low BMD were included in the study.

Interview-cum-questionnaire method was used for collecting general information of the subjects. Information regarding their age, occupation, marital status, family type, educational level, occupation and educational level of spouse, family and per capita income was recorded. The assessment of nutritional status of the subjects was done by dietary survey, anthropometric measurements and biochemical investigation of blood before and after $\mathrm{NC}$ for a period of four months. The dietary survey was conducted for 3 consecutive days using 24 hours recall method. For calculating daily nutrient intake of macronutrients and micronutrients of each subject, 'MSU nutriguide software' developed by Song et al (1992) was used. The adequacy of nutrients was assessed by comparing the nutrient intake with Recommended Dietary Allowances (RDA) of ICMR (2011). Anthropometric measurements of height, body weight, waist circumference, and hip circumference of the subjects were recorded before and after NC using standard methods (Jelliffe, 1966). Serum calcium was analyzed by oCPC method (Gitelman, 1967) and Dual Energy X-Ray Absorptiometry (DEXA) was used for measuring Bone Mineral Density of the subjects, two times, one at the beginning of the survey and second after four months of experimentation. DEXA was performed by the laboratory technicians with the Pronosco X-Posure System. The Principle for DEXA is: X- Rays are used to produce images of spine, hip, forearm or even the whole body. X-rays are composed of two energy levels which are absorbed differently by the bones in the body. A computer is able to determine from these differences how much bone mineral is present. The spine, hip and forearm are measured because that is where osteoporotic fractures occur the most.

Nutrition education was imparted to the subjects twice a month, for a period of four months. On the basis of their dietary pattern they were given knowledge about the sources of calcium and how to include those in their daily diet. A sub-sample consisting of 30 respondents having serum calcium levels less than $9 \mathrm{mg} / \mathrm{dl}$ were selected. The effect of dietary calcium intake after four months was seen by analyzing their serum calcium. The data collected was statistically analyzed using mean, standard error, student's t-test and Karl Pearson's coefficient of correlation $(r)$ using Microsoft Excel (2010) statistical analysis tool pack.

\section{RESULTS AND DISCUSSION}

Data revealed that the mean age of the respondents was 49.5 years with majority between the age-group of 45-55 years, whereas Singh (2012) found that average age of menopause in Hyderabad women was 46 years which was lower than 
Jain, S. and Verma, S. / J. Appl. \& Nat. Sci. 10 (4): 1281-1285 (2018)

Table 1. General Information of the post menopausal women of Ludhiana City.

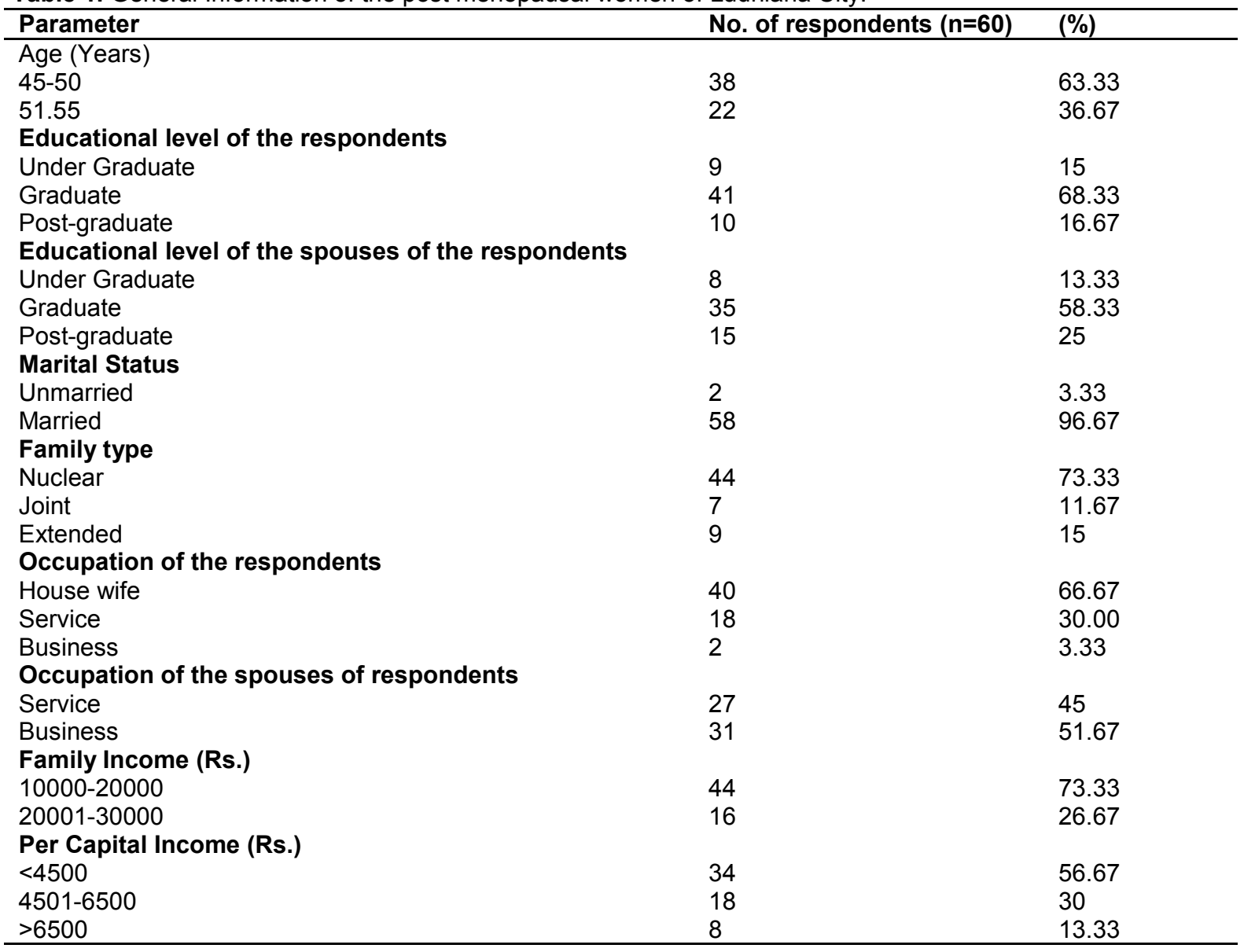

Table 2. Change in the \% adequacy of food intake after NC $(n=60)$.

\begin{tabular}{lccc}
\hline Food Group & Before & After (4 months) & Suggested Intake $^{\mathbf{1}}$ g/day \\
\hline Cereals & 82.33 & 88.77 & 300 \\
Pulses & 72.17 & 71.17 & 60 \\
Milk and Milk Products & 83.2 & 98.33 & 300 \\
Roots and Tubers & 57.6 & 81.3 & 100 \\
GLV & 18.8 & 49.32 & 100 \\
Other Vegetables & 34.47 & 58.9 & 100 \\
Fruits & 53.1 & 101.5 & 100 \\
Sugar and Jaggery & 104.5 & 86 & 20 \\
Fats and Oils & 151 & 92.5 & 20 \\
\hline
\end{tabular}

${ }^{1}$ ICMR (2011)

the present study. According to Ceylan and Ozerdogan (2015), age of menopause could be attributed to a number of factors like mother's age at menopause, age at menarche, gestational age, use of oral contraceptives, irregular menstrual cycle, number of pregnancies, BMI, use of tobac$\mathrm{co}$ and alcohol and physical activity. Most of the women were married and belonged to nuclear families, having family members upto four. Most of the subjects, that is, $73.33 \%$ had monthly family income in the range of Rs. 10,000 to Rs. 20,000 . Mean per capita monthly income of the subjects was Rs. 4915. The subjects and their spouses were well-educated, that is, $68.33 \%$ of the subjects were graduates. Whereas $58.33 \%$ of the spouses of the subjects were graduates. Majority of the respondents $(66.67 \%)$ were housewives. Forty five \% spouses of respondents were in service and $51.67 \%$ were in business.

The mean height of the respondents was 156.8 $\mathrm{cm}$. The mean body weight decreased significantly $(P<0.01)$ from 72.03 to $69.97 \mathrm{~kg}$ which resulted in decrease of BMI from 29.53 to $28.68 \mathrm{~kg} / \mathrm{m}^{2}$.

Nutrition education resulted in significant changes in food intake of the post menopausal women. The intake of milk and milk products increased significantly $(P<0.05)$ from 250 to $295 \mathrm{~g}$. The intake of roots and tubers, (58 to $81 \mathrm{~g}$ ), GLVs (19 to $49 \mathrm{~g}$ ), other vegetables (34 to $59 \mathrm{~g}$ ) and fruits (53 to $102 \mathrm{~g}$ ) increased significantly $(P<0.01)$ whereas the in- 
Jain, S. and Verma, S. / J. Appl. \& Nat. Sci. 10 (4): 1281-1285 (2018)

Table 3. Average daily nutrient intake by the post menopausal women of Ludhiana City before and after NC.

\begin{tabular}{lllll}
\hline Food Group & Before & After (4 months) & t- value & RDA $^{\mathbf{1}}$ \\
\hline Energy (Kcal) & $2244.42 \pm 22.1$ & $2132.33 \pm 13.38$ & $4.58^{*}$ & 1700 \\
Protein (g) & $48.18 \pm 1.08$ & $49.05 \pm 2.34$ & -0.36 & 50 \\
Total Fat (g) & $125.12 \pm 5.12$ & $74.12 \pm 2.46$ & $8.89^{*}$ & 40 \\
b-carotene (mcg) & $880.02 \pm 80.43$ & $1183 \pm 52.07$ & $-3.55^{*}$ & 2400 \\
Thiamine (mg) & $1.26 \pm 0.26$ & $1.883 \pm 0.07$ & 1.42 & 1.0 \\
Riboflavin (mg) & $1.14 \pm 0.06$ & $1.11 \pm 0.07$ & 0.32 & 1.1 \\
Niacin (mg) & $5.12 \pm 0.98$ & $22.2 \pm 1.10$ & $-6.44^{*}$ & 12 \\
Vitamin C (mg) & $85.92 \pm 11.62$ & $98.92 \pm 9.8$ & $-2.47^{* *}$ & 40 \\
Iron (mg) & $16.73 \pm 0.99$ & $21.92 \pm 0.99$ & $-3.67^{*}$ & 30 \\
Calcm (mg) & $618.28 \pm 24.16$ & $967.93 \pm 33.85$ & $-8.12^{*}$ & 900 \\
Phosphorus (mg) & $861.58 \pm 36.99$ & $1088.32 \pm 54.76$ & $2.49^{* *}$ & 1000 \\
\hline
\end{tabular}

* Significant at $1 \%,{ }^{* *}$ Significant at $5 \%,{ }^{1}$ ICMR (2011)

Table 4. Serum calcium and bone mineral density of the post menopausal women of Ludhiana city.

\begin{tabular}{llll}
\hline & Before & After (4 months) & t-value \\
\hline Serum Ca $(\mathrm{mg} / \mathrm{dl})(\mathrm{n}=30)$ & $7.82 \pm 0.11$ & $8.99 \pm 0.16$ & $-6.48^{*}$ \\
BMD (T-score) $(\mathrm{n}=60)$ & $-2.2 \pm 0.11$ & $-2.01 \pm 0.01$ & $-2.48^{* *}$ \\
\hline
\end{tabular}

* Significant at $1 \%,{ }^{* *}$ Significant at $5 \%$

Table 5. Classification of subjects according to T-scores.

\begin{tabular}{llll}
\hline Diagnosis & T-score & $(\mathbf{n}=6 \mathbf{0})$ & \\
\cline { 2 - 4 } & & Before & After (4 months) \\
\hline Osteopenia & -1 to -2.5 & $40(66.67)$ & $48(80)$ \\
Osteoporosis & $<-2.5$ & $20(33.33)$ & $12(20)$ \\
\hline
\end{tabular}

( ) = Figures in parentheses represent \%ages.

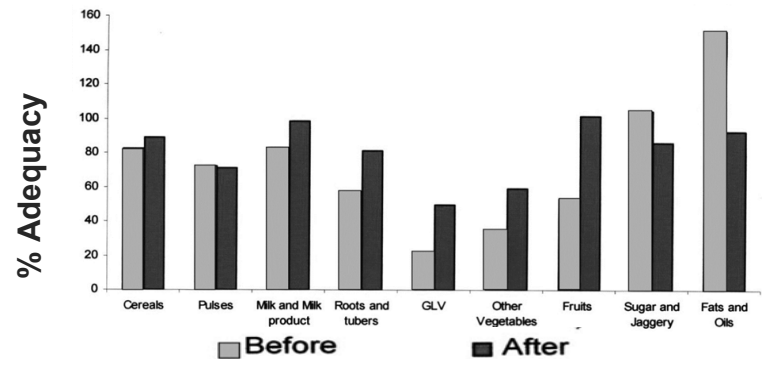

Fig. 1. Change in percent adequacy of food intake after ( Four Months)

take of sugar and visible fats and oils decreased significantly $(P<0.01)$ from 21 to $17 \mathrm{~g}$ and 30 to $18 \mathrm{~g}$ respectively in the respondents. Subsequently, there was a significant decrease $(P<0.01)$ in the intake of energy from 2244 to 2132 kcal. Overall energy intake by Punjabi post menopausal women as recorded by Kushwaha (2011) in Punjab was $1975 \mathrm{kcal}$ which is lower than the present intake. Hence the \% energy contribution from carbohydrates increased from 48 to $52 \%$ and from fats decreased from 43 to $37 \%$ which was still higher than the recommendations of $20 \%$ energy from fats / oils (ICMR 2011). There was significant increase in the intake of carotene, vitamin $\mathrm{C}$, iron, calcium and phosphorus after N.C. However, the intake of proteins, b-carotene and iron was still less than the RDAs.

The biochemical assessment of the subjects revealed that the serum calcium level of subjects improved significantly $(P<0.01)$ from 7.82 to 8.99 $\mathrm{mg} / \mathrm{dl}$ but was still less than the standard range of
$9-11 \mathrm{mg} / \mathrm{dl}$. The $\mathrm{t}$-score of the BMD value increased significantly $(P<0.02)$ from -2.2 to -2.01 in subjects. The subjects were classified as osteopenics and osteoporotic on the basis of their tscores. Majority $(66.67 \%)$ of the subjects were osteopenic and rest $(33.33 \%)$ of the subjects were osteoporotic. But after NC, the \%age of osteopenic subjects further increased to $80 \%$ and the percentage of osteoporotic subjects decreased to $20 \%$.

Thus, as the dietary intake of fats and oils and sugar and jaggery decreased and the intake of fruits, GLVs, other vegetables and milk products increased, lead to decreased intake of energy and total fat and significant increase in niacin, vitamin C, calcium, phosphorus and iron. This eventually lead to an in serum calcium levels and BMD.

\section{Conclusion}

It was concluded that with better nutrition, especially intake of calcium rich foods, appropriate physical activities and exposure to sunlight for vitamin $D$ synthesis in skin would also be valuable. NC imparted to menopausal women significantly decreased the intake of fats and oils and sugar and jaggery $(p<0.01)$ but increased the intake of fruits, GLVs, other vegetables $(p<0.01)$ and milk and milk products $(p<0.05)$. Hence the intake of energy and total fat reduced which helped decrease their BMI from 29.52 to $28.68 \mathrm{~kg} /$ $\mathrm{m}^{2}(\mathrm{p}<0.01)$. A significant improvement in serum calcium levels from 7.82 to $8.99 \mathrm{mg} / \mathrm{dl}$ was seen $(p<0.01)$. The $t-s c o r e$ of BMD value also increased 
from -2.2 to -2.01 which was significant at $5 \%$ level of significance. Not only school children and adolescents should be targeted for providing nutrition education but their parents and teachers can also be sensitized regarding the role of calcium rich foods for optimal development of peak bone mass. On the other hand, pregnant and lactating mothers and older individuals also need to be educated in order to reduce age related bone loss.

\section{REFERENCES}

1. Ceylan, B. and Ozerdogan, N.(2015). Factors affecting age of onset of menopause and determination of quality of life in menopause. Turk. J. Obstet. Gynecol.,12(1):43-49

2. Chowdhary, D. (2012). Nutritional and Lifestyle factors for the risk for the risk assessment of osteoporosis in pre and post menopausal women. M.Sc. thesis, Punjab Agricultural University, Ludhiana, India.

3. Deepti, L., Joyti Lakshmi, and Prakash, J. (2006) Diet related risk factor for osteroporosis in per and postmenopousal Indian women. The. Ind. J. Nutr. Dietet. 43: 341.

4. Dempster, D. W. and Lindsay, R. (1993) Pathogenesis of osteoporosis. Lancet., 341: 797-801.

5. Gitelman, H. J. (1967). An improved automatic pro- cedure for the determination of calcium in biologic specimens. Anal Biochem., 18: 521.

6. ICMR (2011). Nutrient requirements and recommended dietary allowances for Indians: A report of the expert group of the Indian Council of Medical Research. New Delhi.

7. Jelliffe, D. B. (1966) The assessment of nutritional status of the community, Monograph Series No. 53. Asian Indian Foods. Nutritional Analysis Computer Programme Michigan State University, USA.

8. Kushwaha, S. (2011). Impact of supplementation of drumstick (Moringa Olifera) and amaranth (Amaranthus tricolor) leaves on the antioxidant status of the post menopausal women. M.Sc. thesis, Punjab Agricultural University, Ludhiana, India.

9. Prasad, P. (2010). Obesity and its associated risk factors among post menopausal women. M.Sc. thesis, Punjab Agricultural University, Ludhiana, India.

10.Singh, M. (2012) Early age of natural menopause in India, a biological marker for early preventive health programs.Climacteric,15(6):581-6.

11.Song, W.O., Mann, S.K., Sehgal, S., Devi, P.R., Guradu, S., and Kakarala, M. (1992) Nutriguide: Asian Indian Foods. Nutritional Analysis Computer Programme. Michigan State University, USA.

12.Susan, N. (2001). Natural thought on menopause. Retreived from www.menopauseonline.com. 